\title{
Use of FACTS Devices for Improvement of Voltage Profile in Power System

\author{
${ }^{* 1}$ S.D. Naik, ${ }^{2}$ Anurag Shrivastava, ${ }^{3}$ Yogesh Awadhiya \\ ${ }^{1,2,3}$ Shri Ramdeobaba College of Engineering and Management, Nagpur \\ Email: ${ }^{1}$ naiksd@rknec.edu, ${ }^{2}$ shrivastavaa_1@rknec.edu, ${ }^{3}$ awadhiyayg@rknec.edu
}

Received: 06th October 2019, Accepted: 20th November 2019, Published: 31st December 2019

\begin{abstract}
The important function of power engineer is to do the planning for best, efficient operation of power system subject to the efficient and best way of power exchange between utility companies. Load flow is universally used as an important tool at planning and design stages of power system. Adequate reactive power management is necessary to maintain voltage profile in power system. The advantages of adequate reactive power control include maintaining power quality and flat voltage profile at all power transmission levels, improvement in power factor, transmission efficiency and system stability. The natural electrical characteristics of the electrical power system can be modified as per the requirements by using Series and Shunt Capacitor compensation techniques. Providing reactive power compensation using shunt and series capacitors and inductors at optimal locations is a well established method to improve the voltage profile in power system. There are several ways to improve power system performance using Static VAR Compensators (SVC). The SVC's are most suitable for regulating voltages, increasing damping of power oscillation and damping synchronous resonances and torsional oscillations. This paper presents the practical results of comparison of performance analysis of power system with compensation (SVC Capacitive) and without compensation and their effect on voltage profile of system. To demonstrate the comparison, the transmission line model of length $180 \mathrm{~km}$ is considered. The experimental work outcome is helpful in designing and operational reactive power planning for maintaining suitable voltage profile in power system.
\end{abstract}

\section{Keywords}

Compensation, FACTS, Reactive power, Voltage profile, VAR, SVC, TCR

\section{Introduction}

The growing increment and usage of electricity worldwide has deregulated power companies into the section of three companies like Generation Company (Gencom), Transmission Company (Transcom) and Distribution Company (Discom). The problem of achieving better voltage control and reliable and secure operation of large power system is greatly simplified using advanced method of analysis and powerful softwares. The power system researchers are forced to shift their focus to improvement of power system stability due to many recurring incidences of blackouts around the world. There are many powerful numerical algorithms and softwares available for power flow analysis that determine the steady state operating characteristics of a power system network from the existing data of transmission lines and buses. Power flow analysis leads to knowing the bus voltages, currents in various transmission lines, active and reactive losses in lines. The planning for future expansion of power systems is possible using power flow analysis. For example, in case of emergency, it may become essential to remove transmission line or transformer from the system. In that case, it must be taken into consideration that the remaining lines in the system handle should be capable of carrying the required load currents without exceeding their thermal limits.[1-2]

A. Methods for power flow analysis

Following are methods of power flow analysis.

1. Newton-Raphson Method (N-R)

2. Gauss-Seidel iteration Method (G-S)

3. Fast-Decoupled Method (FD)

Among these methods, N-R method is widely used because of its advantages over the other method [3]. The load flow simulations and analysis can be done using various powerful softwares like PSAT, MATLAB, Power World Simulator and ETAP etc.

B. Newton Raphson method

It is an important and widely used method for solving non-linear power flow equations of large power system networks. The convergence of N-R method is faster as compared to G-S method. The only disadvantage of this method is that it requires large computer memory. But with the advent in storage systems this disadvantage is nullified. Figure 1 shows the flowchart of N-R method [4]. 


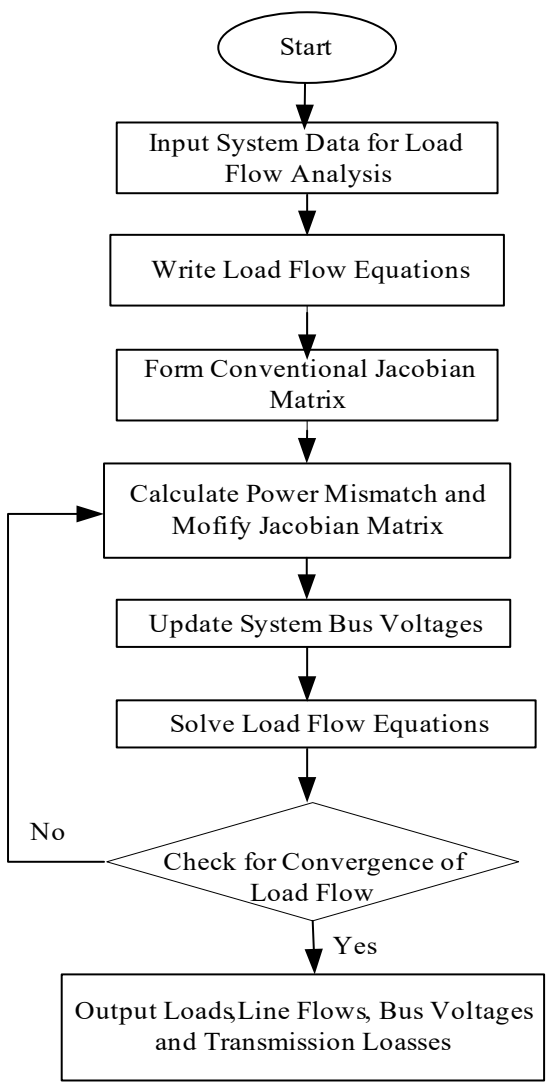

Figure 1: Flowchart of N-R Method

C. Transmission Line Model: The transmission line under consideration is $180 \mathrm{~km}$. long. The line may be used as $180 \mathrm{~km}$ for three phase representation or $540 \mathrm{~km}$ for single phase representation. The $180 \mathrm{~km}$ line is divided into six sections. Each section is $30 \mathrm{~km}$ long and represented as pi model. In each pi section line inductance is considered for every $30 \mathrm{~km}$ and capacitance for every $15 \mathrm{~km}$. The actual values of line parameters of a $220 \mathrm{kV}$ transmission line are $0.03333 \Omega / \mathrm{km}, 1.06 \mathrm{mH} / \mathrm{km}$ and $7.33 \mathrm{nF} / \mathrm{km}$. The power carrying capacity of transmission line is $1000 \mathrm{~W}$. The transmission line model used for practical analysis is shown in Figure 2 (a).

D. Generating Station: The Generating Station is shown with a generator model to feed the transmission line. The sending end is provided with a step down transformer from which different ranges of voltages of $110 \mathrm{~V}$ or $220 \mathrm{~V}$ can be obtained. Tap changing switches are provided for selecting voltage range. Ammeters and voltmeters are provided at sending end of transmission line to measure currents and voltages. The Generating Station is externally connected to the transmitting section. The Generating Station used for practical analysis is shown in Figure 2 (b).

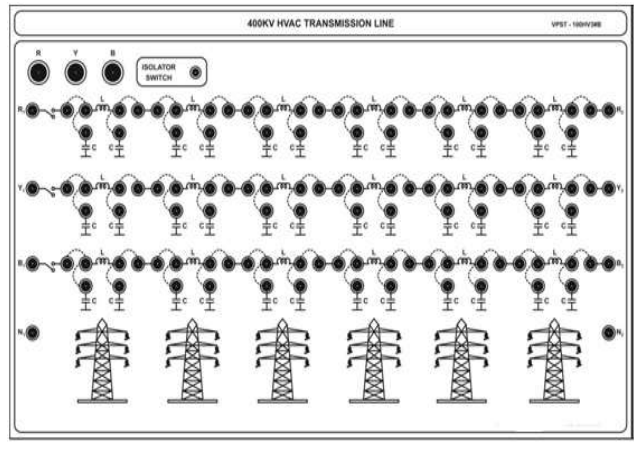

Figure 2(a): Transmission Line Model

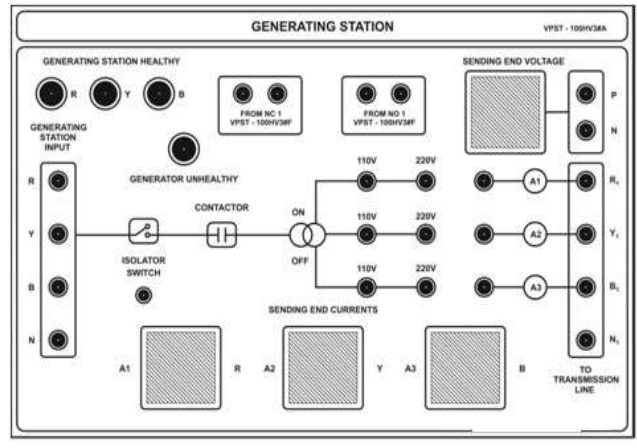

Figure 2(b): Generating Station 
E. Receiving Station: The receiving station is provided with a step up transformer to obtain different ranges of voltage of $110 \mathrm{~V}$ or $220 \mathrm{~V}$. Ammeters and voltmeters are provided at receiving end of transmission line to measure currents and voltages. The receiving station is externally connected to the RLC loading section. The receiving station used for practical analysis is shown in Figure 3(a).

F. R-L Loading Section: The loading section is provided with resistive and inductive load. The loading section is also provided with an ammeter to measure the load current and a voltmeter to measure the load end voltage. The R-L loading section used for practical analysis is shown in Figure 3(b).

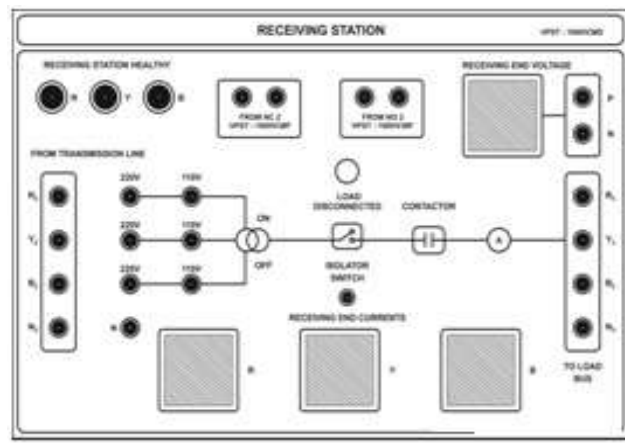

Figure 3(a): Receiving Station

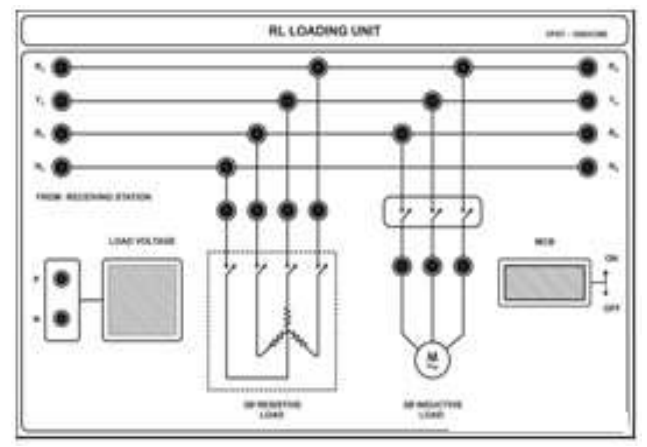

Figure 3(b): RL Loading Unit

G. Reactive Power Compensation Techniques: There are many compensating techniques described in literature and used in practice like shunt compensation, series compensation, static VAR compensation, synchronous condensers etc. In this paper more emphasis is given on the static VAR compensation technique. This technique is discussed in detail as given below.

Static VAR Compensator: The Static VAR Compensator (SVC) device belongs to the family of Flexible AC Transmission System (FACTS). The FACTS devices work on the principle of power electronics to control power flow on power grids. The terminal voltage of SVC is regulated by controlling the amount of reactive power injected into or absorbed from the power system. SVCs can be used in both ways. In case of low system voltage the SVC injects reactive power into the system (SVC capacitive) [5][6] and in case of high system voltage, it absorbs reactive power from the system (SVC inductive). The mode and variation of reactive power is achieved by connecting three-phase capacitor banks and inductor banks connected on secondary side of coupling transformer. In its simplest form, the SVC is nothing but Thyristor Controlled Reactor (TCR) in parallel with a bank of capacitors. From an operational point of view, the SVC behaves like a shunt-connected variable reactance, which either generates (capacitive mode) or absorbs (inductive mode) reactive power in order to regulate the voltage magnitude at the point of connection to power network. With SVC it is possible to achieve fast reactive power control and on line voltage regulation. The SVCs have almost negligible time delay and faster speed of response which can be achieved by the fine tuning of firing angle control of Thyristor [7] Structure of SVC is represented in Figure 4.

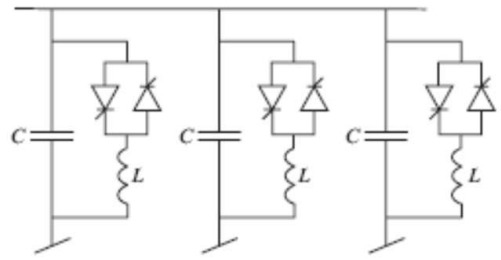

Figure 4: Structure of an SVC

Figure 4 shows that SVC is a shunt-connected device comprising of several modules built up using a parallel combination of a variable capacitance and thyristor controlled reactor [7].

Experimental Work and Results:

The generating station supplies a combination of resistive and inductive load at $220 \mathrm{~V}$. Bus voltage for each section of transmission line was observed without compensation and with Static reactive power compensation (Capacitance $=2.0 \mu \mathrm{f}$ and firing angle $\left.=180^{\circ}\right)$. The compensation is provided at receiving end bus using TCR . The bus voltages with and without compensation are recorded in the Table 1 and Table 2 . After using static VAR compensation with reactive power injection of 27.51 VAR, it is found that voltage profile of each bus of transmission line was improved considerably. [8].A comparison between voltage profile of buses with and without Static VAR compensation is shown in Figure 5.[9][10][11] 


\begin{tabular}{|c|c|}
\hline BUS & VOLTAGE \\
\hline 1 & 211 \\
\hline 2 & 200 \\
\hline 3 & 193 \\
\hline 4 & 184 \\
\hline 5 & 175 \\
\hline 6 & 165 \\
\hline
\end{tabular}

Table 1: Bus Voltages without Compensation

\begin{tabular}{|c|c|}
\hline BUS & VOLTAGE \\
\hline 1 & 215 \\
\hline 2 & 210 \\
\hline 3 & 205 \\
\hline 4 & 198 \\
\hline 5 & 192 \\
\hline 6 & 186 \\
\hline
\end{tabular}

Table 2: Bus Voltages with Compensation

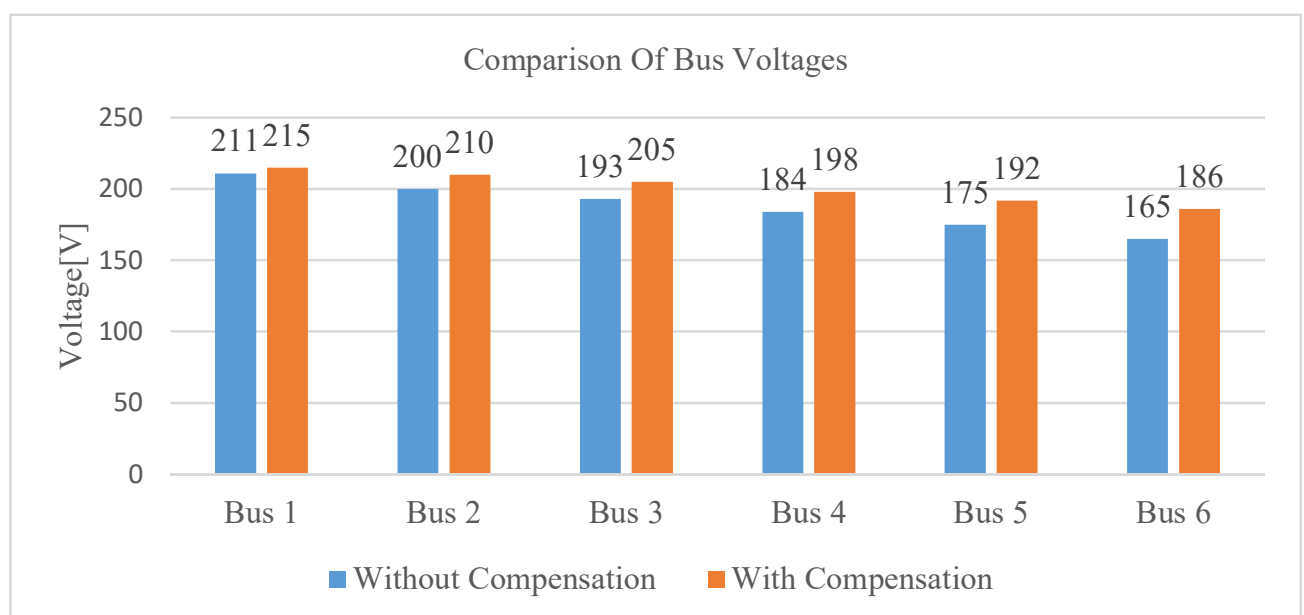

Figure 5: Comparisons of Bus Voltages with and Without Reactive Power Compensation

\section{Conclusion}

A capacitor is well known source of the reactive power generation. Static VAR Compensator is used in the power system to supply or absorb excess the reactive power required by the transmission line. Static VAR Compensation added to transmission lines is widely used to improve and maintain the voltage profile in the power system. Under voltage adversely affects performance of loads such as induction motors, light bulbs, etc. Whereas over voltage is the main cause of magnetic saturation and resultant harmonic generation. This may lead to equipment failures due to insulation breakdown. Therefore, maintaining the required voltage levels is important for proper operation and utilization of loads. From the results we can infer that providing compensation is most effective and powerful technique for maintain reactive power balance in power system and helps power system to operate in most efficient way.

\section{References}

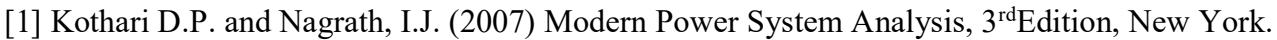

[2] Afolabi, O.A., Ali, W.H., Cofie, P., Fuller, J., Obiomon, P. and Kolawole, E.S. (2015) Analysis of the Load Flow Problem in Power System Planning Studies. Energy and Power Engineering, 7, 509-523.

[3] C.L.Wadhwa, (1986), Electrical Power Systems, Second Edition, Wiley Eastern Limited.

[4] Prabha Kundur "Power system stability and control" TATA McGraw-Hill Edition, Power System Engineering Series.2006.

[5] Oum El FadhelLoubaba, Bekri\& Fellah, Mohammed-Karim. (2008). The Static Var Compensator (SVC) Device in the power systems Using MATLAB Sim Power Systems.

[6]Siddalinga. S. Nuchhi, Raghavendra. B. Sali, Dr.Shekhappa G. Ankaliki (2013) Effect Of Reactive Power Compensation On Voltage Profile, International Journal of Engineering Research \& Technology (IJERT), ISSN: 2278-01881, Vol. 2 Issue 6, June - 2013. 
[7] T. Tamilarasi, Dr. M. K. Elango “A Review on Facts Devices in Power System for Stability Analysis", International Journal of Trend in Research and Development, Volume 3(2), ISSN: 2394-9333,2016.

[8] S.D.Naik et al "Effects of Generator Reactive Power Limit on Proximity to Voltage Instability of Multibus Power System " $12^{\text {th }}$ IEEE conference on Industrial Electronics and Applications, ICIEA 2017 Siem Reap ,Cambodia , 18-20 June 2017.

[9] M. Maheshkumar, "A Study of Reactive Power Compensation in Power System and Its Compensation Techniques" International Journal of Enovation in Engineering and Technology (IJEIT), Special Issue NCRTEEFOSS-2016, ISSN: 2319-1058,pp:251-256.

[10] Paserba, J.J.; "How FACTS controllers benefit AC transmission systems", Power Engineering Society General Meeting, IEEE, Vol.2, June 2004, pp: 1257 - 1262.

[11]G.Sivagnanam, Dr. K. Venkatatachalam, Dr.H.Abdul Rauf, "Reactive Power Compensation in Power Transmission Network Using FACTS devices", International Journal of Applied Engineering Research, ISSN 0973-4562 Vol. 10 No.56 (2015),pp:184-188. 